\title{
Synthesis and application of hetaryl disazo disperse dyes derived from 4-amino-2-chloro-6,7-dimethoxyquinazoline and 3-chloroaniline on polyester fabric
}

\author{
J. O. OTUTU ${ }^{1 *}$, E.K. OSSAI ${ }^{1}$ and S.U. AMEURU ${ }^{2}$ \\ ${ }^{I}$ Department of Chemistry, Faculty of Science, Delta State University, P.M.B. 1, Abraka, Delta State, Nigeria. \\ ${ }^{2}$ Department of Textile Science and Technology, Ahmadu Bello University, Zaria. \\ *Corresponding author, E-mail: johnsonotutu@gmail.com
}

\begin{abstract}
In an attempt to find more environmentally friendly azo dyes, the synthesis and application of disazo disperse dye derivatives of 4-amino-2-chloro-6,7-dimethoxyquinazoline and 3-chloroaniline on polyester fabric are reported. The disazo dyes were synthesized via diazotisation of 3- chloroaniline and coupled with 4-amino2-chloro-6,7-dimethoxyquinazoline to afford an intermediate azo dye. This intermediate was further diazotised in concentrated sulphuric acid and followed by coupling reactions with various coupling components such as 1,3-diyhydroxybenzene, 2-amino-6-methylbenzonitrile, 3-amino-5-methyl-prazole, 1-napthol and 7-methoxy2-naphthol to give the disazo disperse dyes. The basic fastness properties (light fastness wash fastness heat and rubbing fastness) of the dyes on polyester fibre were discussed in terms of their chemical structures. All the synthesized disazo disperse dyes were characterized on the basis of their spectral analyses, IR, ${ }^{1} \mathrm{H} N \mathrm{NR},{ }^{13} \mathrm{C}$ NMR and UV-visible spectroscopic data. The light fastness results were observed to be good ratings (5) and very good ratings (5/6). The sublimation test results gave excellent ratings of (5). Also, it was found that the wash fastness property, which is an indicator whether a dye could have affinity for a textile fabric or not, have excellent ratings of 5. From these results, it can be concluded that the best of these disazo dye compounds could be commercially important in the textile industry.
\end{abstract}

(C) 2015 International Formulae Group. All rights reserved.

Keywords: Disazo dyes, disperse dyes, hetaryl compounds, fastness, polyester fib, quinazoline.

\section{INTRODUCTION}

Azo dyes are used to colour diverse materials including textiles, leather, plastics, paper, cosmetics and food. The azo dyes are usually formulated using aromatic amines (Joseph et al., 2010; Neifar et al., 2013). Thus, they are characterized by the presence of one or more azo groups substituted with aromatic amines. The aromatic amines are capable of being regenerated by reduction processes during usage. Some of these aromatic amines have been found in recent times to be harmful to consumers and so have been classified as carcinogenic and genotoxic by the International Agency for Research on Cancer (WHO, 2010; Yaman et al., 2013). Since aromatic amines are bioaccumulative and toxic to aquatic life, there is growing concern about the potential risk of these harmful aromatic amines passing down the food chain 
to consumers. This is not all, the toxicity and allergic reactions of some of these synthetic dyes are becoming more and more worrisome from the consumers point of view (Wang et al., 2007; Deveoglu et al., 2013). On the basis of these problems, the emphasis on the use of the heterocyclic amines in the synthesis of azo dyes, has come under focus. The attraction of the heterocycles stems from their significance in medicine, agriculture, industry and academic research and teaching. The interesting and often intriguing structural and electronic properties of heterocyclic compounds often naturally occurring, has led to their use in many areas of human endeavour. The heterocycles both natural and synthetic are known to have good biological and pharmaceutical activities (Szczepankiewicz et al., 2000; Kidwai and Priya, 2008). For instance, the 4-amino-2chloro-6,7-dimethoxyquinazoline which is one of the precursors for this study, has been found to exhibit excellent anticancer activity (Canbell et al., 1987; Joseph et al., 2010; Selvan and Kumar, 2011). No study has been reported on the synthesis of disazo disperse dyes from this intermediate. The objective of this work therefore, is to synthesize disazo disperse dyes from 4-amino-2-chloro-6,7dimethoxyquinazoline and 3-chloroaniline. The characterization of the dyes was carried out using ${ }^{\prime} \mathrm{H}$ NMR, ${ }^{13} \mathrm{C}$ NMR IR and UVvisible analyses. Furthermore, the authors want to evaluate the fastness properties of the dyes on polyester fabric.

\section{MATERIALS AND METHODS}

All the chemicals used in the synthesis of the dyes were of commercial grade and were used as received. The coupling components were sourced from Merck. The confirmatory establishment of structure of all the newly synthesized disazo compounds was done by melting points, TLC, IR, ${ }^{1} \mathrm{H}$ and ${ }^{13} \mathrm{C}$ NMR and UV-visible analyses.

The purity of the disazo compounds was checked by TLC using chloroformmethanol (95:5) and toluene-acetic acid (90:10), Thin Layer-Chromatography (TLC) was performed on aluminium sheets, silica gel 60 coated plate, $\mathrm{F}_{254}, 0.2 \mathrm{~mm}$ (Merck).

All melting points were recorded on electrothermal 9100 apparatus and are uncorrected. Infrared spectra were recorded $\begin{array}{llll}\text { using a Shimadzu (8400S) FT-IR } & \end{array}$ spectrometer. ${ }^{1} \mathrm{H}(199.97 \mathrm{MHz})$ and ${ }^{13} \mathrm{C}$ $(50.28 \mathrm{MHz})$ nuclear magnetic resonance (NMRs) were reported on Mercury 200BB series spectrometer. Deuterated chloroform $\left(\mathrm{CDCI}_{3}\right)$ and dimethylsulphoxide (DMSO- $\left.\mathrm{d}_{6}\right)$ were used as NMR solvents. Chemical shifts were reported in parts per million (ppm) downfield from internal tetramethysilane (TMS). UV-vis absorption spectra were recorded on Genesys $10 \mathrm{~S}$ V 1.20 spectrometer.

\section{Synthesis of Dye 3}

The amine for diazotization, 3chloroanline $(6 \mathrm{ml})$ was dissolved in sulphuric acid $(98 \%, 7 \mathrm{ml})$ and diazotized by dropwise addition of sodium nitrite $(4.64 \mathrm{~g}, 32.1 \mathrm{mmol}$ in $10 \mathrm{ml}$ water) at $\mathrm{O}{ }^{\circ} \mathrm{C}$. An excess of nitrous acid was detected using starch iodide paper. A dark blue colour showed excess nitrous acid which indicated the formation of the diazonium salt. The 4-amino-2-chloro-6,7dimethoxyquinazoline $(10.0 \mathrm{~g}, 44.3 \mathrm{mmol})$ was dissolved in acetic acid $(10 \mathrm{ml})$. The diazotized amine was added dropwise and stirred at room temperature for $2 \mathrm{~h}$. The precipitate that was formed was isolated by filtration and washed with water to afford 3chlorophenylazo-2, 3-dimethoxy-7chloroquinazoline in $87 \%$ yield.

\section{3-Chlorophenylazo-2,3-dimethoxy-7- chloroquinazolineazo $\quad 2^{1}$,4-dihydroxybenzene} (5a)

Compound 3 (1.87 g, $8.3 \mathrm{mmol})$ was mixed with $30 \mathrm{ml}$ water and diazotised in conc. $\mathrm{H}_{2} \mathrm{SO}_{4}(5 \mathrm{ml})$ by dropwise addition of sodium nitrite solution $(3.0 \mathrm{~g}, 4.5 \mathrm{mmol}$ in 10 $\mathrm{ml}$ water) with stirring for over 15 minutes. Excess nitrous acid was destroyed using urea $(0.15 \mathrm{~g}, 3 \mathrm{mmol})$. 1,3-dihydroxybenzene (1.0 g, 10.9 mmol) was dissolved in sodium hydroxide solution $(1.0 \mathrm{~g}, 25 \mathrm{mmol}$ in $20 \mathrm{ml}$ 
water). The diazonium salt solution was added slowly with vigorous stirring. The precipitate obtained after further stirring for 2 hours was isolated by filtration, washed with water and recrystallized from ethanol to afford brown crystals. The solvent-system used for TLC was chloroform-methanol (95:5)

3-Chlorophenylazo-2,3-dimethoxy-7chloroquinaoline azo-4-amino-2 ${ }^{1}$-methyl benzonitrile (5b)

Compound $3(1.87 \mathrm{~g}, 8.3 \mathrm{mmol})$ was diazotised in concentrated sulphuric acid (5 $\mathrm{ml}$ ) by the addition of sodium nitrite solution (3.0 g, $43.5 \mathrm{mmol}$ in $10 \mathrm{ml}$ water) with stirring over 15 minutes. 2-amino-6methylbenzonitrile $(1.09 \mathrm{~g}, 8.3 \mathrm{mmol})$ was dissolved in acetic acid $(5 \mathrm{ml})$. The diazotised amine was added dropwise and stirred at room temperature for $2 \mathrm{~h}$ and left to stand overnight. The precipitate formed was isolated by filtration, washed with water and purified by recrystallization from carbontetrachloride to give brown crystals. The solvent-system used for TLC was toluene-acetic acid (90:10).

3-Chlorophenylazo-2, 3-dimethoxy-7chloroquinazolineazo- $2^{1}$-amino-5-methyl prazole (5c)

Compound $3(1.87 \mathrm{~g}, 8.3 \mathrm{mmol})$ was diazotized in concentrated sulphuric acid ( $98 \%, 5 \mathrm{ml})$, by adding sodium nitrite solution $(3.0 \mathrm{~g}, 43.5 \mathrm{mmol}$ in $10 \mathrm{ml}$ water) with stirring for over 15 minutes. The 3 -amino-5methylpyrazole $(0.804,8.3 \mathrm{mmol})$ was dissolved in $4 \mathrm{ml}$ acetic acid. The diazotised compound (3), was added dropwise and stirred at room temperature for $1.5 \mathrm{~h}$. The precipitate formed was isolated by filtration, washed with water and recrystallized from carbontetrachloride. The Thin Layer Chromatographic (TLC) solvent-system used was chloroform-methanol (95:5).

\section{3-Chlorophenylazo-2,3-dimethoxy-7-} chloroquinazolineazo-1-naphthol. (5d) Compound $3(1.87 \mathrm{~g}, 8.3 \mathrm{mmol})$ was diazotized in conc. $\mathrm{H}_{2} \mathrm{SO}_{4}(98 \%, 5 \mathrm{ml})$ by treating it with cold sodium nitrite solution
( $3.0 \mathrm{~g}, 43.5 \mathrm{mmol}$ in $10 \mathrm{ml}$ water) and stirred for over 15 minutes. Excess nitrous acid was destroyed using urea $(0.15 \mathrm{~g}, 3 \mathrm{mmol})$. The coupling component, 1-naphthol (1.18 g, 8.3 mmol) was dissolved in sodium hydroxide solution $(1.3 \mathrm{~g}, 37.5 \mathrm{mmol}$ in $20 \mathrm{ml}$ water). The diazonium salt solution was added slowly and the reaction mixture vigorously stirred at room temperature for 1 hour. The precipitate formed was isolated by filtration, washed with water, and dried. The crude product was purified by recrystallization from dimethylformamide-water (2:1) to give brown crystals. The solvent-system used for TLC was chloroform-methanol (95:5).

\section{3-Chlorophenylazo-2, 3-dimethoxy-7- chloroquinazolineazo-7-methoxy-2- naphthol (5e) \\ Compound $3(1.87 \mathrm{~g}, 8.3 \mathrm{mmol})$ was} mixed with $40 \mathrm{ml}$ water and diazotised in conc. $\mathrm{H}_{2} \mathrm{SO}_{4}(98 \%, 5 \mathrm{ml})$ by adding sodium nitrite solution $(3.0 \mathrm{~g}, 43.5 \mathrm{mmol}$ in $10 \mathrm{ml}$ water) at $0-5{ }^{\circ} \mathrm{C}$ with stirring for over 15 minutes. The 7-methoxy-2-naphthol $(1.44 \mathrm{~g}$, $8.3 \mathrm{mmol}$ ) was dissolved in $10 \mathrm{ml}$ acetic acid. And the diazotised compound 3 was added dropwise and stirred vigorously for $1 \mathrm{~h}$ and left to stand overnight. The precipitate formed was isolated by filtration, washed with water and air-dried. The crude product was washed with $\mathrm{CCl}_{4}$ to afford brown crystals of compound (5e). The TLC solvent-system used was toluene-acetic acid (90:10).

\section{Dye application}

The dyebaths were prepared with the disazo disperse dyes 5a- $5 \mathrm{e}$ using Lignosulfonate-sulphite Liquors as the dispersing agent. The dye was dissolved in dimethylformamide followed by adding the dispersing agent at liquor to good ratio of $20: 1$. The $\mathrm{pH}$ of the dyebath was adjusted to 4.5- 5.5 with acetic acid. N-butanol was added to the dyebath to improve the levelness of the dyes on the polyester fabric. The polyester fabric was dipped into the dye dispersion in the dyebath and dyeing was continued for 60 minutes at $130{ }^{\circ} \mathrm{C}-135{ }^{\circ} \mathrm{C}$ under increased 
pressures. Each dyed polyester fabric was subjected to reduction-clearing process at 85 ${ }^{\circ} \mathrm{C}$ for 10 minutes in a solution with a Liquor ratio of $20: 1$, including $2 \mathrm{gl}^{-1}$ sodium dithionite (Merck), hydrosulphate $2 \mathrm{gl}^{-1}$ and a betaine amphoteric surfactant $2 \mathrm{gl}^{-1}$ in water, washed with water and then dried.

\section{Fastness Tests \\ Wash Fastness}

The wash fastness of the reductioncleared polyester samples were tested according to International Standard Organisation method (ISO, 105-CO6, 1994). The composite samples measuring $(10 \times 5 \mathrm{~cm})$ were treated with standard soap solution $2 \mathrm{gl}^{-1}$, sodium carbonate $2 \mathrm{gl}^{-1}$ and Liquor ratio 50:1 for 30 minutes at $60{ }^{\circ} \mathrm{C}$ in a Linitest machine. The change in colour and degree of staining of adjacent undyed fabrics were evaluated using the greyscales $1-5$ (water 1 is poor and 5 is excellent).

\section{Light Fastness}

The light fastness of the (2\% owf) dyeings were determined using an Atlas ES 25 Weather-Ometer (Xenon arc) according to AATCC test method (AATCC, 16- 2001). The test conditions were: Black panel temperature: $60^{\circ} \mathrm{C}$, Relative humidity: $30 \pm 5$ $\%$, chamber temperature: $50{ }^{\circ} \mathrm{C}$. Irradiance: $0.75 \mathrm{Wm}^{-1}$, counter setting: $54 \mathrm{kJm}^{-2}$. The tested samples were exposed to these conditions and the changes in colour were evaluated by comparing them with the standard blue wools grades $1-8$ (where 1 is poor and 8 is excellent).

\section{Heat (Sublimation) Fastness}

Colour fastness to heat (sublimation) was tested according to ISO 105-POl, 1993 standard method (ISO, 1993). The dyed fabric samples were treated in a sublimation testing machine at $177{ }^{\circ} \mathrm{C}$ for $30 \mathrm{sec}$ after heat setting at $180{ }^{\circ} \mathrm{C}$ for $60 \mathrm{sec}$. The change in colour of the tested fabric samples were compared with the standard greyscales (grade 1-5).

\section{Rub Fastness}

The colour fastness to rubbing was tested using ISO 105-X12, 2001 (ISO, 2001) $\mathrm{Y}$ (B) 5.71-11 crockmeter. The change in colour of the tested dyed fabric samples were evaluated by comparing with the standard greyscales grade 1-5 (where 1 is poor and 5 is excellent)

\section{RESULTS}

The synthesis of quinazoline disazo disperse dye derivatives (5a-5e) was carried out according to scheme 1. Characterization data of the synthesized disazo compounds are given below and their physical properties were shown in Table 1.

The colour fastness properties such as wash, light, sublimation and rubbing were performed on the dyed polyester fabric and the results were given in Tables 2 and 3. The wash fastness values were found to be grade 5 and staining of adjacent multi-fibre fabrics showed grade 4/5. In Table 3, the light fastness properties obtained with the disazo dyes was good, being grade $5 / 6$ in general on the blue wool reference scale. The heat (sublimation) fastness of dyed samples gave excellent grades of 5 . The rubbing fastness results showed a colour change of grade 4 in the case of dry rubbing and grade $3 / 4$ in the case of wet rubbing.

Synthesis of 3-chlorophenylazo-2, 3dimethoxy-7-chloroquinazolineazo-2,4hydroxybenzene (5a)

Compound (5a) was synthesized by diazotising dye 3 and coupling with 1,3dihydroxybenzene under alkaline conditions. The yield obtained was $79 \%$ having molecular formula $\mathrm{C}_{22} \mathrm{H}_{16} \mathrm{~N}_{4} \mathrm{Cl}_{2}$ and molecular weight $499 \mathrm{gmol}^{-1}$. The observed melting point was $180{ }^{\circ} \mathrm{C}$ and the $\mathrm{R}_{\mathrm{f}}$ of TLC was 0.32 (chloroform:methanol (95:5)). The structure was confirmed by IR, ${ }^{1} \mathrm{H} \mathrm{NMR},{ }^{13} \mathrm{C}$ NMR and UV-visible analyses as follows:

FT-IR $\left(\mathrm{KBr}, \mathrm{vcm}^{-1}\right)$ : 3527, 3522, 3398 (O$\left.\mathrm{H}_{\mathrm{str}}\right) 3171,3161,3149$ (C-Hstr), 1597, 1541 
(Aromatic stretches), $1442(\mathrm{~N}=\mathrm{N}), 1213(\mathrm{C}$ Ostr), 1134, $1031\left(\mathrm{O}-\mathrm{CH}_{3}\right), 788\left(\mathrm{C}-\mathrm{Cl}_{\mathrm{str}}\right)$.

${ }^{1} \mathrm{H} \quad \mathrm{NMR} \quad\left(\mathrm{DMSO}-\mathrm{d}_{6}, \delta_{\mathrm{H}} / \mathrm{ppm}\right): 3.83$ $\left(6 \mathrm{H}, \mathrm{s}, 2 \times \mathrm{OCH}_{3}\right) 4.41(\mathrm{IH}, \mathrm{s}, \mathrm{OH}), 6.42-7.10$ (2H, d, J.8.MHz, 2 x ArH) $7.60(1 \mathrm{H}, \mathrm{s}, \mathrm{ArH})$, 7.80 (1H, s, ArH), 8.25-9.95(2H, s, ArH).

${ }^{13} \mathrm{C}$ NMR (DMSO-d $\left.\mathrm{d}_{6}, \delta_{\mathrm{C}} / \mathrm{ppm}\right): 162.69$, $158.17, \quad 155.55, \quad 149.07,147.47,131.40$, $131.06, \quad 129.70, \quad 129.01, \quad 106.49,105.37$, $105.00,103.62,56.73,56.59,56.44,41.14$, $40.72,40.30,39.88,39.87,39.46,39.05$, 38.63 .

$\lambda_{\max }(\mathrm{DMF}, \mathrm{nm}): 443$

Synthesis of 3-chlorophenylazo-2,3dimethoxy-7-chloroquinazolineazo-4amino-2 ${ }^{1}$-methylbenzonitrile (5b)

Compound (5b) was synthesized via diazotisation of dye 3 and coupling with 2amino-6-methylbenzonitrile under acidic conditions. The yield of the pure product was $71 \%$ having molecular formula $\mathrm{C}_{24} \mathrm{H}_{18} \mathrm{~N}_{8} \mathrm{O}_{2} \mathrm{Cl}_{2}$ and molecular weight 521 gmol $^{-1}$. The melting point observed was 171 ${ }^{\circ} \mathrm{C}$ while the $\mathrm{R}_{\mathrm{f}}$ value of TLC using tolueneacetic acid (90:10) solvent-system was 0.25. The structure of compound $5 \mathrm{~b}$ was confirmed by IR, ${ }^{1} \mathrm{H}$ NMR, ${ }^{13} \mathrm{C} \mathrm{NMR}$ and UV-visible analyses as:

FT-IR (KBr, vcm $\left.{ }^{-1}\right): 3311,3163\left(\mathrm{NH}_{2}\right)$, 2937, 2841 (C-Hstr), 2513, $2266(\mathrm{C}=\mathrm{N})$, 1633, 1558, 1502 (Aromatic stretches), 1442, $1402(\mathrm{~N}=\mathrm{N}), 1134,1072\left(\mathrm{O}-\mathrm{CH}_{3}\right), 759(\mathrm{C}-$ $\mathrm{Cl}_{\text {str }}$ ).

${ }^{1} \mathrm{H}$ NMR (DMSO-d $\left.6, \delta_{\mathrm{H}} / \mathrm{ppm}\right): 2.45$ $\left(2 \mathrm{H}, \mathrm{s}, \mathrm{NH}_{2}\right) 3.95\left(3 \mathrm{H}, \mathrm{s}, \mathrm{CH}_{3}\right), 5.65(6 \mathrm{H}, \mathrm{s}, 2$ $\left.\mathrm{x} \mathrm{OCH}_{3}\right), 6.90-7.00(2 \mathrm{H}, \mathrm{d}, \mathrm{J}=8.4 \mathrm{~Hz}, \mathrm{ArH})$, $7.10(\mathrm{IH}, \mathrm{s}, \mathrm{ArH}), 7.62(1 \mathrm{H}, \mathrm{s}, \mathrm{ArH}), 8.61$ $(1 \mathrm{H}, \mathrm{s}, \mathrm{ArH})$.

${ }^{13} \mathrm{C}$ NMR (DMSO-d 6 , $\left.\delta \mathrm{c} / \mathrm{ppm}\right): 162.59$, $155.91,152.81,149.33,143.88,106.10$, 103.94, 103.81, 56.67, 56.57, 41.14, 40.73, 39.88, 39.48, 39.05, 38.64 .

$\lambda_{\max }(\mathrm{DMF}), \mathrm{nm}: 631$.

Synthesis of 3-chlorophenylazo-2,3dimethoxy-7-chloroquinazolineazo-2 ${ }^{1}$ amino-5-methylpyrazole $(5 \mathrm{c})$

The titled compound was synthesized via diazotisation of compound 3 and coupling with 3-amino-5-methylpyrazole in an acidic medium. Yield: $65 \%$, molecular formula: $\mathrm{C}_{20} \mathrm{H}_{17} \mathrm{~N}_{9} \mathrm{~N}_{9} \mathrm{O}_{2} \mathrm{Cl}_{2}$, molecular weight: 486 gmol $^{-1}$, m.p: $182{ }^{\circ} \mathrm{C}$ and $\mathrm{R}_{\mathrm{f}}$ (Chloroformmethanol (95:5)) was 0.28 structure was confirmed by IR, ${ }^{1} \mathrm{H}$ NMR, ${ }^{13} \mathrm{C}$ NMR and UV-Visible analyses as:

FT-IR $\left(\mathrm{KBr}, \mathrm{vcm}^{-1}\right): 3410,3325\left(\mathrm{NH}_{2}\right)$, 3163, 2954 (C-Hstr), 2546, 2528 (NH), 1610, 1541, 1508 (Aromatic stretches), 1442, 1402 $(\mathrm{N}=\mathrm{N}), 1095,1055,1022\left(\mathrm{O}-\mathrm{CH}_{3}\right), 786,731$ (C-Clstr).

${ }^{1} \mathrm{H}$ NMR (DMSO-d $\left.\mathrm{d}_{6}, \delta_{\mathrm{H}} / \mathrm{ppm}\right): 2.21-$ $2.43\left(4 \mathrm{H}, \mathrm{s}, 2 \times \mathrm{NH}_{2}\right) 3.81\left(3 \mathrm{H}, \mathrm{s}, \mathrm{CH}_{3}\right), 5.60$ $\left(6 \mathrm{H}, \mathrm{s}, 2 \times \mathrm{OCH}_{3}\right), 6.25(1 \mathrm{H}, \mathrm{s}, \mathrm{ArH}), 6.65$ (1H, s, ArH), 7.10-7.65 (2H, d. J.8.5Hz, ArH), $11.84(\mathrm{NH})$.

${ }^{13} \mathrm{C} \quad \mathrm{NMR} \quad$ (DMSO- $\left.\mathrm{d}_{6}, \quad \delta \mathrm{c} / \mathrm{ppm}\right)$ : $162.79, \quad 145.19, \quad 143.22, \quad 142.00,122.60$, $93.09,56.61,41.12,40.71,40.30,39.87$, 39.45, 39.04, 38.61, 11.50,10.39.

$\lambda_{\max }(\mathrm{DMF}), \mathrm{nm}: 551$

Synthesis of 3-chlorophenylazo-2, 3dimethoxy-7-chloroquinazolineazo-1naphthol (5d)

Compound (5d) was synthesized via diazotisation of dye 3 and coupling with 1naphthol in an alkaline medium. Yield: $61 \%$, molecular formular: $\mathrm{C}_{26} \mathrm{H}_{18} \mathrm{~N}_{6} \mathrm{O}_{3} \mathrm{Cl}_{2}$, molecular weight: 533 gmol $^{-1}$, m.p: $265{ }^{\circ} \mathrm{C}, \mathrm{R}_{\mathrm{f}}$ $=0.22$. Structure was confirmed by IR, ${ }^{1} \mathrm{H}$ NMR, ${ }^{13} \mathrm{C}$ NMR and UV-visible analyses as: FT-IR $\left(\mathrm{KBr}, \mathrm{vcm}^{-1}\right)$ : 3321, $3180(\mathrm{O}-$ Hstr $), \quad 2845 \quad\left(\mathrm{C}-\mathrm{H}_{\text {str }}\right), \quad 1631, \quad 1568,1508$ (Aromatic stretches), $1442(\mathrm{~N}=\mathrm{N}), 1255$, $1213\left(\mathrm{C}-\mathrm{O}_{\text {str }}\right), 1112,1045\left(\mathrm{O}-\mathrm{CH}_{3}\right), 773(\mathrm{C}-$ $\mathrm{Cl}_{\text {str }}$ ).

${ }^{1} \mathrm{H} \quad \mathrm{NMR} \quad\left(\mathrm{DMSO}-\mathrm{d}_{6}, \delta_{\mathrm{H}} / \mathrm{ppm}\right): 3.81$ $\left(6 \mathrm{H}, \mathrm{s}, 2 \times \mathrm{OCH}_{3}\right) 4.10(\mathrm{IH}, \mathrm{s}, \mathrm{OH}), 6.80-7.23$ (6H, m, naphthyl- H) $7.41-8.18$ (5H, s, ArH).

${ }^{13} \mathrm{C}$ NMR (DMSO-d $\left.6, \delta \mathrm{c} / \mathrm{ppm}\right): 162.20$, 155.55, 14915, 108.94, 106.46, 103.67, 56.76, $15.59,41.41,40.99,40.16,39.75,39.39$, 38.01 .

$\lambda_{\max }(\mathrm{DMF}), \mathrm{nm}: 840$ 
Synthesis of 3-chlorophenylazo-2, 3dimethoxy-7-chloroquinazolineazo-7methoxy-2-naphthol (5e)

The tilted compound was synthesized via diazotisation of dye 3 and coupling with 7methoxy-2-naphthol in an acid medium. Yield: $55 \%$, molecular formula $\mathrm{C}_{27} \mathrm{H}_{20} \mathrm{~N}_{6} \mathrm{O}_{4} \mathrm{Cl}_{2}$, molecular weight 563 gmol $^{-1}$, $\mathrm{R}_{\mathrm{f}}$ 0.31. The structure of the compound was confirmed by IR, ${ }^{1} \mathrm{H}$ NMR, ${ }^{13} \mathrm{C}$ NMR and $\mathrm{UV}$-visible analyses as:

FT- IR $\left(\mathrm{KBr}, \quad \mathrm{vcm}^{-1}\right): 3313,3111$ (Ar-OH) 2937, 2843 (Ar C-H str ), 1631, 1568, 1506 (Aromatic stretches), 1444, $1408(\mathrm{~N}=\mathrm{N})$,
1217 (C-Ostr), 1134, $1043\left(\mathrm{O}-\mathrm{CH}_{3}\right), 759$ (C$\mathrm{Cl}_{\text {str }}$ ).

${ }^{1} \mathrm{H} \quad \mathrm{NMR} \quad\left(\mathrm{DMSO}-\mathrm{d}_{6}, \delta_{\mathrm{H}} / \mathrm{ppm}\right): 3.84$ $\left(9 \mathrm{H}, \mathrm{s}, 3 \times \mathrm{OCH}_{3}\right), 4.71(\mathrm{IH}, \mathrm{s}, \mathrm{OH}), 6.81(2 \mathrm{H}$, $\mathrm{d}=8.2 \mathrm{~Hz}, \mathrm{ArH}), 7.10-7.40(5 \mathrm{H}, \mathrm{s}, \mathrm{ArH})$, 7.62-8.46 (3H, s, ArH).

${ }^{13} \mathrm{C} \mathrm{NMR}\left(\mathrm{CDCl}_{3}, \delta \mathrm{c} / \mathrm{ppm}\right): 162.86,156.11$, 153.32, 149. 54, 144.54, 106.41, 104.46, $94.62,56.89,56.81,41.39,40.98,40.56$, 40.14, 39.72, 39.31, 38.89 .

$\lambda_{\text {max }}(\mathrm{DMF}), \mathrm{nm}: 666$.

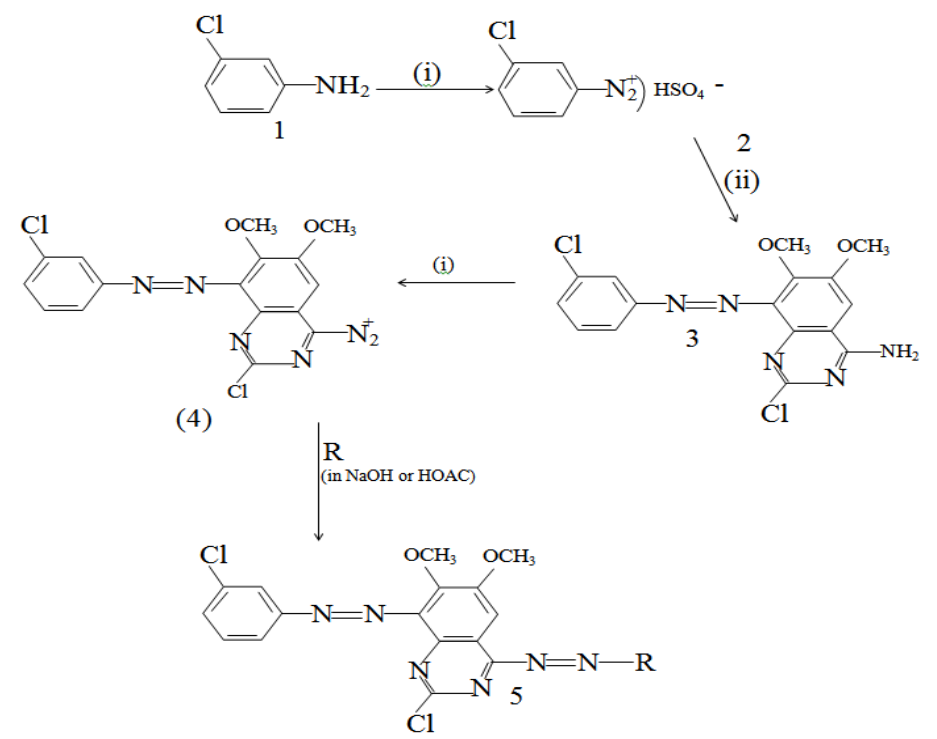

Where $\mathrm{R}$ are as follows:

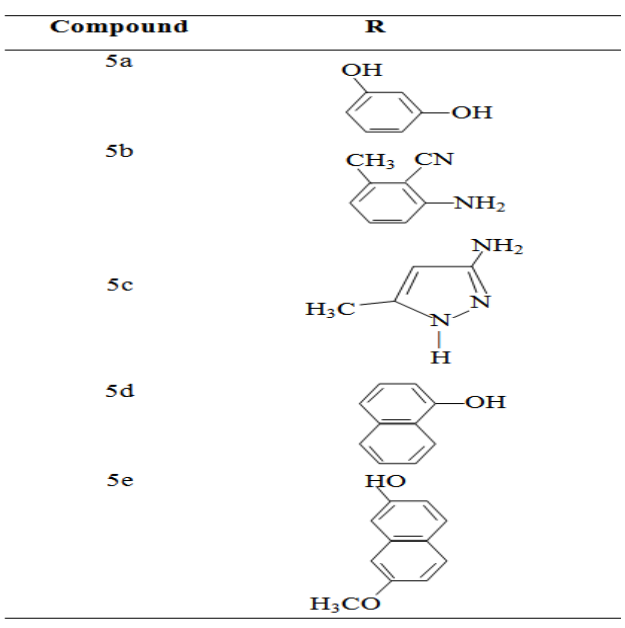


Figure 1: Scheme of disazo dye compounds synthesis. (i) $\mathrm{H}_{2} \mathrm{SO}_{4} / \mathrm{N}_{\mathrm{a}} \mathrm{NO}_{2}, 0-5{ }^{\circ} \mathrm{C}$, (ii) $\mathrm{C}_{10} \mathrm{H}_{10} \mathrm{~N}_{2} \mathrm{O}_{2} \mathrm{Cl}$ (iii) $\mathrm{HOAC}$ $=$ Acetic acid.

Table 1: Physicochemical properties of synthesized disazo disperse dyes.

\begin{tabular}{lccccc}
\hline Dye compound & Molecular formula & M.Wt $\left(\right.$ gmol $\left.^{-1}\right)$ & Yield (\%) & M.pt ( $\left.^{\mathbf{0}} \mathbf{C}\right)$ & $\mathbf{R}_{\mathbf{f}}$ \\
\hline $5 \mathrm{a}$ & $\mathrm{C}_{22} \mathrm{H}_{16} \mathrm{~N}_{6} \mathrm{O}_{4} \mathrm{Cl}_{2}$ & 499 & 79 & 180 & 0.32 \\
$5 \mathrm{~b}$ & $\mathrm{C}_{24} \mathrm{H}_{18} \mathrm{~N}_{8} \mathrm{O}_{2} \mathrm{Cl}_{2}$ & 521 & 51 & 171 & 0.25 \\
$5 \mathrm{c}$ & $\mathrm{C}_{20} \mathrm{H}_{17} \mathrm{~N}_{9} \mathrm{O}_{2} \mathrm{Cl}_{2}$ & 486 & 65 & 182 & 0.28 \\
$5 \mathrm{~d}$ & $\mathrm{C}_{26} \mathrm{H}_{18} \mathrm{~N}_{6} \mathrm{O}_{3} \mathrm{Cl}_{2}$ & 533 & 61 & 265 & 0.22 \\
$5 \mathrm{e}$ & $\mathrm{C}_{27} \mathrm{H}_{20} \mathrm{~N}_{6} \mathrm{O}_{4} \mathrm{Cl}_{2}$ & 563 & 55 & 195 & 0.31 \\
\hline \multicolumn{2}{r}{ m.wt: molecular weight, M.pt: melting point } & & &
\end{tabular}

Table 2: The Wash fastness properties of disazo dyes $5 \mathrm{a}-5 \mathrm{e}$ (2\% owf) on polyester fabric

\begin{tabular}{ccccccc}
\hline Dye & $\begin{array}{c}\text { Change in } \\
\text { Colour }\end{array}$ & Acetate & \multicolumn{5}{c}{ Staining } \\
\cline { 4 - 7 } & & & Cotton & Nylon & Polyester & Acrylic \\
$5 \mathrm{a}$ & 5 & $4 / 5$ & 5 & $4 / 5$ & $4 / 5$ & $4 / 5$ \\
$5 \mathrm{~b}$ & 5 & $4 / 5$ & 5 & 5 & 5 & $4 / 5$ \\
$5 \mathrm{c}$ & 5 & $4 / 5$ & $4 / 5$ & $4 / 5$ & 5 & $4 / 5$ \\
$5 \mathrm{~d}$ & 5 & 5 & $4 / 5$ & $4 / 5$ & $4 / 5$ & $4 / 5$ \\
$5 \mathrm{e}$ & 5 & 5 & 5 & 5 & 5 & $4 / 5$ \\
\hline
\end{tabular}

Table 3: The Light, sublimation and rub (crocking) fastness properties of disazo dye 5a- 5e (2\% owf) on polyester fabric.

\begin{tabular}{|c|c|c|c|c|c|}
\hline Dye & Light & Sublimation & $\begin{array}{c}\text { Rubbing } \\
\text { Dye }\end{array}$ & $\begin{array}{c}\text { Staining } \\
\text { Wet }\end{array}$ & $\begin{array}{l}\text { Colour on dyed } \\
\text { polyester fabric }\end{array}$ \\
\hline $5 a$ & 5 & 5 & 4 & $3 / 4$ & Orange \\
\hline $5 b$ & $5 / 6$ & 5 & 4 & $3 / 4$ & Orange \\
\hline $5 c$ & 5 & 5 & $3 / 5$ & $3 / 4$ & Orange- brown \\
\hline $5 d$ & $5 / 6$ & 5 & $4 / 5$ & 4 & Orange- brown \\
\hline $5 e$ & $5 / 6$ & 5 & 4 & $3 / 4$ & orange \\
\hline
\end{tabular}

Grey scale ratings are 1-8 for light fastness in which 1 is poor, and 8 is excellent. The grey scale ratings for other agencies are 1-5 in which 1 is poor and 5 is excellent.

\section{DISCUSSION}

Hetaryl disazo disperse dye compounds were successfully synthesized from 4- amino2-chloro-6, 7-dimethoxyquinazoline and 3chloroaniline. Their structures were confirmed from their respective spectral data such as IR, ${ }^{1} \mathrm{H}$ NMR, ${ }^{13} \mathrm{C}$ NMR and UV- visible studies. The results showed that the compound $(5 \mathrm{~b})$ gave a lowest percentage yield of $51 \%$. This may be attributed to the electron-withdrawing substituents in the coupler aromatic ring
(Karci, 2005; Mao et al., 2013). Also, the reason why compound $(5 \mathrm{e})$ gave a yield of $55 \%$ is not immediately understood, however, the acidic medium under which the coupler component was coupled could be responsible. Compound 5a, 5c and 5d exhibited relatively high yields possibly due to the fact that their coupler agents contain electron rich auxochromic substituents. This is in agreement with the results obtained by several authors (Karci, 2005; Lee et al., 2005). 
For the evaluation of the colour fastness properties of the dyed polyester fabric samples, colour fastness to light, sublimation, dry and wet crocking and to washing at $60{ }^{\circ} \mathrm{C}$ were determined. The light fastness of the dyed polyester fabrics were generally moderate to good (5/6) grades. This moderate to good dye-fibre photostability may be attributable to the relative positions of the halogen atoms and the high crystalline nature of the polyester fibre (Otutu, 2012). Dye (5b) was expected to exhibit a higher light fastness gradings as a result of the $\mathrm{CN}$ group, but due to the fact that its position is not ortho to the azo group, its effect was not felt.

All the dyes exhibited excellent fastness grades to heat (sublimation). This can be attributed to the increase in polarity of the dyes as well as large molecular size (Metwally et al., 2013). Furthermore, there was no staining on the adjacent multi-fibre fabric in the case of dry crocking. However, slight staining was seen on the adjacent multi-fibre fabrics in the case of wet crocking. It was also observed that the wet rubbing fastness test results showed lower grades than the dry rubbing results. This indicates that during wet rubbing, water molecules may have enhanced the removal of colour from the dyed fabric (Mao et al., 2013). In the case of wash fastness, the colour change was found to be excellent (grade 5) and the staining test results of adjacent multi-fibres were generally found to be 4-5 greyscale ratings. This suggests that the dyes have high affinity for the polyester fibre (Gundogan and Eren, 2014). In our previous study, the monoazo dyes of the quinazoline derivatives showed wash fastness values that were a little lower than the values obtained in this report (Otutu et al., 2013). Thus, the excellent wash fastness results shown by the dyes may be due to the large molecular size of the disazo dyes.

\section{Conclusion}

The disazo disperse dye derivatives of 4-amino-2-chloro-6,7-dimethoxy-quinazoline and 3-chloroaniline were synthesized and characterized. The azo compounds were also evaluated for their fastness properties on polyester fabric. The fastness results showed excellent washing and sublimation fastness grades. The light and rubbing fastness were moderate to good. From the results of the study, it can be concluded that the synthesized azo disperse dyes have very good affinity for polyester fibre and could be very useful in the textile industry.

\section{REFERENCES}

American Association of Textile Chemists and Colourists (AATCC) 2001. Test Method 16 - 2001. Colour fastness to light (Research Triangle Park: AATCC, 2001).

Campbell SF, Davey MJ, Hardstone JD, Lewis BN, Palmer MJ. 1987. 2,4-Diamino-6,7dimethoxyquinazolines, 2-(4-(4-(1,4Benzo-diazan-2-ylcarbonyl) pipera-zin-1yl). Derivatives as $\alpha$, Adrenaceptor Antagonists and Antihypertensive Agents. Am. J. Med. Chem., 30: 51- 57.

Deveoglu O, Erkan G, Torgan E, Karadag R. 2013. The Evaluation of procedures for dyeing silk with buckthorn and Walloon oak on the basis of colour changes and fastness characteristics. Color Technol, 129(3): 223- 231.

Edwards LC, Freeman HS. 2005. Synthetic dyes based on environmental considerations. Part 3: Aquatic toxicity of iron-complexed azo dyes. Colour Technol., 121(3): 265- 270.

Gundogan S, Eren HA. 2014. Practical realisation of ozone clearing after disperse dyeing of polyester. Color Technol., 130(5): 357-362.

Hobson DK, Wales DS. 1998. Green dyes. How the production of anthraqunone dyes can be environmentally sound. J. Soc. Dyers Colour, 114: 42- 44.

ISO 105 X12: 2001. Textiles-Tests for colour fastness - Part X12: Colour fastness to rubbing (Basel: ISO, 2000).

ISO 105-CO6: 1994. Textiles-Tests for colour fastness - Part CO6: Colour fastness to 
Domestic and Commercial Laundering (ISO 105-CO6, 1994).

ISO, 105-POI: 1993. Textiles-Tests for colour fastness - Part PO1: Colour fastness to sublimation.

Joseph A, Aravinda P, Srinirasan KK, Tukaram K, Angel TT, Jessy EM, Rageev KS. 2010. Synthesis and anticancer activity of some novel 3-(1,3,4thiadiazol-2-yl)-quinazolin- 4-(3H)-ones. Orbital Elect. J. Chem. Camp Grande, 2(2): 158- 167.

Karci F. 2005. Synthesis of disazo dyes derived from heterocyclic components. Color Technol., 121(5):237-290.

Kidwai M, Priya. 2008. Synthesis of quinazoline analogues using sodium perborate as catalyst. India J. Chem., 47B: $1876-1881$.

Lee JJ, Lee WJ, Choi JH, Kim JF. 2005. Synthesis and application of temporarily solubilised azo disperse dyes containing sulphatoethylsulphone group. Dyes and Pigm., 65(2): 75-81.

Mao YH, Guan Y, Zheng QK, Liu QS, Feng XN, Wang XX. 2013. Carrier dyeing of polyphenylene sulphide fabric with disperse dyes. Color Technol., 129(1): 39-48.

Metwally MA, Bondock S, El-Desouky ES, Abdou MM. 2013. A facile synthesis and tautomeric structure of novel 4arylhydrazono-3-(2-hydroxyphenyl)-2pyrazolin-5-ones and their application as disperse dyes. Color Technol., 129(6): 41-424.

Neifar A, Abdelmalek IB, Bouajila G, Kolsi R, Bradai MN, Abdelmouleh A, Garygouri A, Ayed N. 2013. Purification and incorporation of the black in cuttlefish Sepia officinalis in eye cosmetic products. Color Technol., 129: 150- 154.

Otutu JO, Efurhievwe EM. 2013. Synthesis of hetercyclic monoazo disperse dyes derived from 4-amino-2-chloro-6, 7dimethoxyquinazoline. J. Applied Sci., 13(6): 924-928.

Otutu JO. 2012. Synthesis of halogenated disazo disperse dyes derived from 2,4dichloroaniline and 3-aminophenol. Curr. Res. Chem., 4(4): 119-127.

Selvan TP, Kumar PV. 2011. Quinazoline marketed drugs - A review. Res Pharmacy, 1(1): 1-21.

Szczepankiewicz W, Suwinski J, Bujok R. 2000. Synthesis of 4Arylaminoquinazolines and 2-Aryl-4arylaminoquinazolines from 2-Aminobenzonitriles, Anilines and formic Acid or Benzaldehydes. Tetrahedron, 56: 9343- 9349.

Wang J, Freeman HS, Claxton LD. 2007. Synthesis and mutagenic properties of 4$4^{1}$-diamino-p-terphenyl and 4,4 ${ }^{1}$-diaminop-quaterphenyl. Color Technol., 123(1): 34- 38.

WHO (World Health Organization). 2010. Some Aromatic Amine Organic Dyes and Related Exposure, IARC Monographs on the Evaluation of Carcinogenic Risks to Humans (vol. 99). International Agency for Research on Cancer, World Health Organization: Lyon.

Yaman Y, Gunduz G, Dukkanci M. 2013. Degradation of CI Reactive Red 141 by heterogeneous fastness- like process over iron- containing ZSM-5 Zeolites. Color Technol., 129(1): $69-75$. 